\title{
Sağlık Okuryazarlığı ve Diabetes Mellitus
}

\author{
Hasan Hüseyin ÇAM ๑ $₫$, Hacı Yusuf GÜLEÇ ๑, Fatma KARASU ๑, Ebru ÖZTÜRK ÇOPUR ๑ \\ Kilis 7 Aralık Üniversitesi Yusuf Şerefoğlu Sağlık Bilimleri Fakültesi Hemşirelik Bölümü, Kilis, Türkiye \\ Bu makaleye yapılacak atıf: Çam HH, Güleç HY, Karasu F, Öztürk Çopur E. Sağlık Okuryazarlığı ve Diabetes Mellitus. Turk J Diab Obes 2021;1: 68-74.
}

\section{ÖZ}

Sağlık okuryazarlığı becerileri, insanların sağlık durumlarındaki potansiyellerini gerçekleştirmek için kullandıkları becerilerdir. Bu beceriler, ya sağlık bilgileri ve hizmetlerini anlamlandırmak ya da başkalarına sağlık bilgileri ve hizmetleri sağlamak için uygulanır. Yetersiz sağlık okuryazarlığı becerileri, daha riskli davranış, daha kötü sağlık, daha az öz yönetim ve daha fazla hastaneye yatma ve maliyet ile ilişkilidir. Sağlık okuryazarlı̆̆ının güçlendirilmesinin bireysel ve toplumsal direnci geliştirdiği, sağlık eşitsizliklerinin ele alınmasında yardımcı olduğu ve sağlık ve refahı iyileştirdiği gösterilmiştir. Sağlık bilgilerine ve hizmetlerine ihtiyacı olan herkesin aynı zamanda sağlık okuryazarlığı becerilerine de ihtiyacı vardır. Sağlık okuryazarlı̆̆ının, diyabet dahil olmak üzere kronik hastalıkların sağlık sonuçlarıyla ilişkili olduğu bilinmektedir. Temel sağlık bakımı alan tip 2 diyabetli hastalarda yetersiz sağlık okuryazarlığı, bağımsız olarak daha kötü glisemik kontrol ve daha yüksek retinopati oranları ile ilişkili bulunmuştur. Yetersiz sağlık okuryazarlığı, dezavantajlı popülasyonlar arasında diyabetle ilgili sorunların orantısız yüküne katkıda bulunmaktadır. Diyabette sağlık okuryazarlığı, diyabet bilgisi, öz-yeterlilik ve öz bakım davranışları ve glisemik kontrol ile ilgilidir. Sağlık okuryazarlı̆̆ı, diyabetli hastalarda görülen ırksal farklılıkların daha iyi anlaşılmasını da sağlayabilir. Bu rolünün anlayışına dayanarak, sağlık okuryazarlığına yönelik stratejiler, diyabet bakımını geliştirmek için olanaklar sağlamaktadır. Bu derlemenin amacı, sağlık okuryazarlığına ilişkin farkındalığı artırmak, sağlık okuryazarlığı ve diyabet ile ilişkilendiren mevcut kanıtları özetlemek ve diyabette sağlık eşitsizliklerini azaltmak için hastalar ve sağlık hizmeti sağlayıcıları arasındaki iletişimi güçlendirmek için stratejiler sunmaktır.

Anahtar Sözcükler: Sağlık okuryazarlı̆̆ı, Diabetes mellitus, Sağlık çıktıları

\section{Health Literacy and Diabetes Mellitus}

\begin{abstract}
Health literacy skills are those people use to realize their potential in health situations. They apply these skills either to make sense of health information and services or provide health information and services to others. Weak health literacy skills are associated with riskier behaviour, poorer health, less self-management and more hospitalization and costs. Strengthening health literacy has been shown to build individual and community resilience, help address health inequities and improve health and well-being. Anyone who needs health information and services also needs health literacy skills to. Health literacy is known to be associated with health outcomes, including chronic disease and diabetes. Among primary care patients with Type 2 diabetes, inadequate health literacy is independently associated with worse glycemic control and higher rates of retinopathy. Inadequate health literacy may contribute to the disproportionate burden of diabetes related problems among disadvantaged populations. In diabetes, health literacy is related to diabetes knowledge, self-efficacy and self-care behaviors and glycemic control. Health literacy may also provide a better understanding of racial disparities observed in patients with diabetes. Strategies to address health literacy, based upon this understanding of its role, provide a means to improve diabetes care. The purpose of this review is to raise awareness of the health literacy, summarize the current evidence linking health literacy and diabetes, and offer strategies to strengthen the communication between patients and health care providers to decrease diabetes health disparities.
\end{abstract}

Keywords: Health literacy, Diabetes mellitus, Health outcomes

ORCID: Hasan Hüseyin Çam / 0000-0002-1722-4727, Hacı Yusuf Güleç / 0000-0002-4277-2514, Fatma Karasu / 0000-0002-7347-0981, Ebru Öztürk Çopur / 0000-0003-1843-3499 


\section{GİRIŞ}

Sağlık okuryazarlığı, kişisel yaşam tarzlarını ve yaşam koşullarını değiştirerek birey ve toplum sağlığını geliştirmek için harekete geçmede bilgi, kişisel beceri ve güven seviyesine ulaşılmasını ifade etmektedir. Bu nedenle, sağlık okuryazarlığı broşür okuyabilmekten ve randevu alabilmekten daha fazlası anlamına gelmektedir. İnsanların sağlık bilgilerine erişimini ve bunları etkili bir şekilde kullanma kapasitelerinin iyileștirilmesi, sağlık okuryazarlığını güçlendirmede kritik önem taşır. Toplumlarda sağlık okuryazarlığının geliştirilmesi, vatandaşların kendi sağlıklarını geliştirmede aktif bir rol oynamalarına, sağlık için toplum eylemleriyle başarılı bir şekilde ilgilenmelerine ve hükümetleri sağlık ve sağlıkta eşitlik konularındaki sorumluluklarını yerine getirmeye zorlamalarına olanak sağlayan bir temel sağlar. En dezavantajlı ve marjinalleşmiş toplumların sağlık okuryazarlığ ihtiyaçlarının karşılanması, özellikle sağlıkta olmak üzere eşitsizliklerin azaltılmasında ilerlemeyi hızlandıracaktır (1).

Sağlık okuryazarlığı düzeyleri, toplumlardaki sosyo-demografik gruplar arasında büyük farklılıklar göstermektedir (2). Amerika Birleşik Devletleri ve Avrupa Birliğinde yapılmış çalışmalar, gelişmiş ülkelerde bile toplumun yaklaşık $\% 50$ 'sinin yetersiz sağlık okuryazarlı̆ğ düzeyinde olduğunu göstermekte iken ülkemizde yapılmış kimi çalışmalar da, toplumun yaklaşı \%70'inin yetersiz sağlık okuryazarlığı düzeyine sahip olduğunu görülmektedir (3). Yetersiz sağlık okuryazarlığı, daha az sağlıklı seçimler, daha riskli sağlık davranışı, daha kötü sağlık durumu, daha az öz yönetim ve daha yüksek maliyetler ve sağlı hizmetlerinin uygunsuz kullanımı ile ilişkilendirilmiştir (2).

Bulaşıcı olmayan hastalıklar, Dünya Sağlık Örgütü Avrupa Bölgesi genelinde önde gelen ölüm nedenlerindendir. Tüm ölümlerin $\% 75$ 'inden fazlası dört kronik hastalıktan birinden kaynaklanmaktadır: kanser, kalp hastalığı, diyabet ve solunum hastalığı. Bulaşıcı olmayan hastalıklar sıklıkla kronik rahatsızlıklara neden olur ve sağlık okuryazarlığı, insanların kronik hastalıkları kendi başlarına yönetebilmelerinde önemli bir rol oynar. Artan sayıda insan, yaşlandıkça bir veya iki kronik hastalığa sahip olup, bu tür insanların $\% 52$ 'si 65 yaşın altındadır. Sağlık okuryazarlığı yetersiz seviyede olan kişiler, kronik veya uzun vadeli durumları günden güne yönetmekte daha fazla zorluk çekmektedir. Bu durum, yaşam tarzını planlamayı ve düzenlemeyi, bilinçli kararlar almayı ve sağlık hizmetlerine ne zaman ve nasıl erişileceğini bilmeyi içermektedir (4).

Kanser, kalp hastalığı ve diyabet gibi bulaşıcı olmayan hastalıklar, birden çok değiştirilebilir risk faktörüyle ilişkili olup, fiziksel aktivite eksikliği, kötü beslenme alışkanlıkları, sigara ve alkol kullanımı bu hastalıkların temel davranışsal belirleyicileridir. Sağlık okuryazarlığı, bu tür sağlık davranışlarıyla ilişkilidir. Sınırlı sağlık okuryazarlığı genellikle bulaşıcı olmayan hastalıkların diğer belirleyicileriyle bağlantılıdır. Örneğin, yetersiz sağlık okuryazarlığı, bulaşıcı olmayan hastalıklar geliştirmeye daha yatkın olan yaşlı nüfus gruplarında, düşük gelirli nüfus gruplarında ve geçiş sürecindeki kültürler arasında daha yaygındır (4).

Dünya çapında, çoğunluğu düşük ve orta gelirli ülkelerde yaşayanlar olmak üzere yaklaşı 422 milyon insan diyabet hastası olup, her yıl 1,6 milyon ölüm doğrudan diyabete bağlı olarak meydana gelmektedir. Hem vaka sayısı hem de diyabet prevalansı son birkaç on yılda giderek artmaktadır. Diyabet, körlük, böbrek yetmezliği, kalp krizi, felç ve alt ekstremite ampütasyonunun başlıca nedenidir. Sağlıklı beslenme, düzenli fiziksel aktivite, normal vücut ağırlığını koruma ve tütün kullanımından kaçınma, tip 2 diyabetin başlangıcını önlemenin veya geciktirmenin yollarıdır. Diyabet tedavi edilebilir ve sonuçları diyet, fiziksel aktivite, ilaç tedavisi ve komplikasyonlara karşı düzenli tarama ve tedavi ile önlenebilir veya geciktirilebilir (4).

Sınırlı okuryazarlık düzeyine sahip diyabetli kişiler için sağlık sonuçları önemli ölçüde geliştirilebilir. Diyabet hastalarının diyabet bilgisi ve öz-yeterlik üzerinde, bir sağlık hizmet sağlayıcısıyla doğrudan temas kurduğu kişiselleştirilmiş eğitim, kişiselleştirilmiş temasın olmadığı multimedya müdahalelerinden daha fazla etkiye sahiptir. Diyabetin yönetilmesine yönelik kapsamlı programlar, sinırlı okuryazarlığa sahip kişilerin klinik sonuçları üzerinde en büyük etkiye sahiptir. Öz yönetim davranışı hedef belirlemeye ve eylem planlarına odaklanan müdahalelerle gelişir (4).

$\mathrm{Bu}$ derlemenin amacı, sağlık okuryazarlığına ilişkin farkındalığı artırmak, sağlık okuryazarlığı ve diyabet ile ilişkilendiren mevcut kanıtları özetlemek ve diyabette sağlık eşitsizliklerini azaltmak için hastalar ve sağlık hizmeti sağlayıcıları arasındaki iletişimi güçlendirmek için stratejiler sunmaktır.

\section{SAĞLIK OKURYAZARLIĞI}

\section{Tanım}

Sağlık okuryazarlığı, bireylerin uygun sağlık kararları alması için gerekli temel sağlık bilgilerini ve hizmetlerini elde etme, işleme ve anlama kapasitesine sahip olma derecesi olarak tanımlanmıştır. Sağlık okuryazarlığı, okuma, dinleme, çözümleme ve karar verme becerilerinin olduğu kompleks bir grubu ve bu becerilerin sağlık durumlarına uygulama becerisini gerektirir. Örneğin, reçeteli ilaç şişeleri, randevu fişleri, tıp eğitimi broşürleri, doktor talimatları ve onay formları ile ilgili talimatları anlama becerisini ve karmaşı sağlık hizmetleri sistemlerini müzakere etme becerisini içermektedir. Daha güncel tanımlar, sağlık hizmeti sistemine ulaşmak için 
gereken belirli becerilere ve sağlık hizmeti sağlayıcıları ile hastalar arasında açık iletişimin önemine odaklanmaktadır. Sağlık okuryazarlığında, hem sağlık hizmeti sağlayıcıları hem de hastalar önemli roller oynamaktadır. Sağlık okuryazarlığı için farklı tanımların sayısı, alanın nasıl geliştiğini de göstermektedir (5).

\section{Avrupa Sağlık Okuryazarlığı Araştırması Kavramsal Modeli}

Son on yılda sağlık okuryazarlığına yönelik birçok kavramsal yaklaşım geliştirilmiştir. Bu yayın, Avrupa Sağlık Okuryazarlığı Araştırması için Avrupa Sağlık Okuryazarlığı Konsorsiyumu tarafından geliştirilen ve sağllk hizmetleri, hastalıkları önleme ve sağlığın geliştirilmesi düzenlemeleri dâhilinde sağlıkla ilgili bilgilere erişme, anlama, değerlendirme ve uygulama yeterlikleri ile ilgili 12 alt sağlık okuryazarlığ boyutunu tanımlayan kavramsal modeli takip etmektedir (Tablo 1) (4).

Sağlık okuryazarlığının tıbbi ve halk sağlığı görüşlerini bütünleștiren bu model ve tanım, kapsamlı literatür incelemelerinde bulunan 17 meslektaş incelemesinden geçmiş tanım ve 12 kavramsal çerçevenin sistematik literatür incelemesi ve içerik analizi yoluyla geliştirilmiştir. Model, sağllk okuryazarlığını geliştirmeye yönelik müdahalelerin geliştirilmesi için bir temel oluşturmakta olup, sağlık hizmetleri, hastalıkları önleme ve sağlığı geliştirme ortamlarında sağlık okuryazarlığının boyutlarını yakalayarak ölçüm araçlarının geliştirilmesi ve doğrulanması için kavramsal bir temel sağlamaktadır. Sağlık okuryazarlığını ölçmek için kapsamlı bir araç olan Avrupa Sağlık Ölçüm Aracı, aşağıda belirtilenler gibi sağlıkla ilgili görevlerin algılanan zorluğunu ölçen 47 soruyla oluşturulmuştur (4):
- Doktorunuzun size ne söylediğini anlamak;

- Kitle iletişim araçlarında hastalıkla ilgili bilgilerin güvenilir olup olmadığını değerlendirmek;

- Stres veya depresyon gibi ruh sağlığı sorunlarının nasıl yönetileceğine dair bilgiyi bulmak;

- Gıda ambalajı hakkındaki bilgileri anlamak;

- Toplumun sağlığını ve iyilik hâlini geliştiren faaliyetlere katılmak.

$\mathrm{Bu}$ anket, sekiz Avrupa ülkesinde (Avusturya, Bulgaristan, Almanya (Kuzey Ren-Vestfalya), Yunanistan, İlanda, Hollanda, Polonya ve İspanya) 1000 kişilik örneklem büyüklügüne sahip popülâsyonlar üzerinde test edilmiştir (4).

\section{Sağlık Okuryazarlığı Nasıl Ölçüllür?}

Sağlık okuryazarlığının kapsamlı bir genel indeksi, 47 sorudan alınan puanlar kullanılarak oluşturulmuş ve 0'dan 50'ye kadar bir ölçeğe dönüştürülmüş olup, 0 en düşük ve 50 en yüksek sağlık okuryazarlığı puanını temsil etmektedir. Buna dayanarak, sağlık okuryazarlığının dört düzeyi -yetersiz, sorunlu, yeterli ve mükemmel sağlık okuryazarlığı- için alt sınırlar ve aralıklar tanımlanmıştır. Savunmasız grupları belirlemek için yetersiz veya sorunlu sağlık okuryazarlığı düzeyi sınırlı sağlık okuryazarlığı olarak tanımlanmıştır. Bu veriler, hem bu ülkeler içinde hem de bu ülkeler arasında karşılaştırmalara izin vermekte olup, aynı zamanda büyük eşitsizlikleri de görünür hâle getirmektedir (4).

\section{Sağlık Okuryazarlığı Neden Önemlidir?}

Güçlü sağlık okuryazarlığı, kişilerin ve ailelerinin sağlıkları hakkında bilinçli kararlar vermeleri için beceri ve güven ge-

Tablo 1: Avrupa Sağlık Okuryazarlığı Araştırması: kavramsal model tarafından tanımlanan 12 alt boyut

\begin{tabular}{lllll}
\hline $\begin{array}{l}\text { Sağlık } \\
\text { okuryazarlığı }\end{array}$ & $\begin{array}{l}\text { Sağlıkla ilgili } \\
\text { bilgileri edinme } \\
\text { veya erişme }\end{array}$ & $\begin{array}{l}\text { Sağlıkla ilgili } \\
\text { bilgileri anlama }\end{array}$ & $\begin{array}{l}\text { Sağlıkla ilgili bilgileri } \\
\text { değerlendirme veya } \\
\text { yargılama, değer biçme }\end{array}$ & $\begin{array}{l}\text { Sağlıkla ilgili bilgileri } \\
\text { uygulama veya kullanma }\end{array}$ \\
\hline Sağlık hizmeti & $\begin{array}{l}\text { 1) Tibbi veya klinik } \\
\text { konularda bilgilere } \\
\text { erişme becerisi }\end{array}$ & $\begin{array}{l}\text { 2) Tibbi bilgileri } \\
\text { anlama ve anlam } \\
\text { çıkarma becerisi }\end{array}$ & $\begin{array}{l}\text { 3) Tibbi bilgileri yorumlama } \\
\text { ve değerlendirme becerisi }\end{array}$ & $\begin{array}{l}\text { 4) Tibbi konularda bilinçli } \\
\text { kararlar verme becerisi }\end{array}$ \\
\hline $\begin{array}{l}\text { Hastalıkların } \\
\text { önlenmesi }\end{array}$ & $\begin{array}{l}\text { 5) Risk faktörlerine } \\
\text { ilişkin bilgilere } \\
\text { erişme becerisi }\end{array}$ & $\begin{array}{l}\text { 6) Risk faktörleri } \\
\text { hakkındaki bilgileri } \\
\text { anlama ve anlam } \\
\text { çıkarma becerisi }\end{array}$ & $\begin{array}{l}\text { 7) Risk faktörlerine ilişkin } \\
\text { bilgileri yorumlama ve } \\
\text { değerlendirme becerisi }\end{array}$ & $\begin{array}{l}\text { 8) Risk faktörleri ile ilgili } \\
\text { bilgilerin uygunluğunu } \\
\text { yargllama becerisi }\end{array}$ \\
\hline $\begin{array}{l}\text { Sağlığı } \\
\text { geliştirme }\end{array}$ & $\begin{array}{l}\text { 9) Sağlık } \\
\text { konularında kendini } \\
\text { güncelleme becerisi }\end{array}$ & $\begin{array}{l}\text { 10) Sağlıkla ilgili } \\
\text { bilgileri anlama } \\
\text { ve anlam çıarma } \\
\text { becerisi }\end{array}$ & $\begin{array}{l}\text { 11) Sağlıkla ilgili konularda } \\
\text { bilgileri yorumlama ve } \\
\text { değerlendirme becerisi }\end{array}$ & $\begin{array}{l}\text { 12) Sağlık sorunları } \\
\text { hakkında yansıyan bir } \\
\text { görüş oluşturma becerisi }\end{array}$ \\
\hline
\end{tabular}

Kaynak: Kickbusch I ve ark. Health literacy: the solid facts. Copenhagen: WHO Regional Office for Europe; 2013. 
liştirmelerini, bakımlarına aktif olarak katılmalarını, sağlık hizmetleri sistemlerinden etkin bir şekilde yararlanmasını, siyasi liderler ve politika yapıcılarınca etkili bir şekilde desteklenmesini sağlar. Sağlık okuryazarlığı duyarlılığı, bazen organizasyonel sağlık okuryazarlığı da denilen önemli başka bir faktördür. Bu faktör, hizmetlerin, kuruluşların ve sistemlerin sağlık okuryazarlığının güçlü yönlerine ve sınırlamalarına göre, sağlık bilgilerine ve mevcut kaynaklara erişilebilir hâle getirme biçimidir. Daha güçlü sağlık okuryazarlığ 1 ve sağlık okuryazarlığı duyarlılı̆̆ı, insanları güçlendirerek ve uygun ortamlar yaratarak sağlık hizmetlerini bireysel yeteneklere bakılmaksızın herkes için erişilebilir hâle getirerek sağlık sonuçlarında eşitliği öne çıkarır (2).

\section{Kültürel Bağlamda Sağlık Okuryazarlığı}

Kültürün iletişimde önemli bir rol oynadığını kabul etmek, sağlık okuryazarlığını daha iyi anlamamıza yardımcı olabilir. Kültür, sağlık okuryazarlığının yalnızca bir parçası olsa da, sağlık okuryazarlığının komplike konusunun çok önemli bir parçasıdır. Amerika Birleşik Devletleri Sağlık ve İnsan Hizmetleri Bakanlığı, "kültürün insanların iletişim kurma, sağlık bilgilerini anlama ve bunlara nasıl tepki verdiklerini etkilediğini" kabul etmektedir. Sağlık hizmetinin kalitesini iyileştirmeye ve maliyetleri düşürmeye yönelik genel çabanın bir parçası olarak "hasta merkezli" sağlık hizmetlerine doğru bir hareket vardır. Etkili iletişimin sağlanması için hastaların ve hizmet sağlayıcıların birlikte çalışması gerekmektedir. Hastaların sağlıkla ilgili kararlarda aktif bir rol alması ve güçlü sağlık bilgisi becerileri geliştirmesi ve aynı zamanda sağlık hizmeti sağlayıcılarının da etkili sağlık iletişimi becerilerini kullanması gerekir (5).

\section{Sağlık Okuryazarlığı İçin Gerekli Beceriler}

Hastalar genellikle karmaşı bilgiler ve tedavi kararlarıyla karşı karşıyadır. Hastaların şunları yapması gerekir:

- Sağlik hizmetlerine erişme

- Göreceli riskleri ve faydaları analiz etme

- Dozajları hesaplama

- Sağlık hizmeti sağlayıcılarıyla iletişim kurma

- Bilgiyi güvenilirlik ve kalite açısından değerlendirme

- Test sonuçlarını yorumlama

- Sağlık bilgilerini bulma

$\mathrm{Bu}$ görevleri yerine getirmek için bireylerde şunlar olması gerekebilir:

- Görsel okuryazar (grafikleri veya diğer görsel bilgileri anlayabilme)

- Bilgisayar okuryazarı (bilgisayar çalıştırabilme)
- Bilgi okuryazarı (ilgili bilgileri edinebilme ve uygulayabilme)

- Sayısal olarak okuryazar (sayısal olarak hesaplayabilme veya mantık yürütebilme)

Sözlü dil becerileri de önemlidir. Hastaların sağlık sorunlarını dile getirmesi ve semptomlarını doğru bir şekilde tanımlaması gerekir. Hastaların ilgili sorular sormaları ve sözlü tıbbi tavsiye veya tedavi talimatlarını anlamaları gerekir. Sağlık bakımı için hekim ve hasta arasında sorumluların paylaşıldığı bir çağda, hastaların güçlü karar verme becerilerine ihtiyacı vardır. İnternetin bir sağlık bilgisi kaynağı olarak gelişmesiyle birlikte sağlık okuryazarlığı, internette arama yapma ve web sitelerini değerlendirme becerisini de içerebilir (5).

\section{Sağlık Okuryazarlığının Etkisi}

Sağlık okuryazarlığı, sağlık sonuçlarını çeşitli şekillerde etkiler.

1. Nüfus gruplarında yüksek sağlık okuryazarlığı oranları toplumlara fayda sağlar.

Sağlık okuryazarı bireyler ekonomik refaha daha aktif bir şekilde katılırlar, daha yüksek kazançlara ve istihdam oranlarına sahiptirler, daha eğitimli ve bilgilidirler, toplum faaliyetlerine daha fazla katkıda bulunurlar ve daha iyi sağlık ve refaha sahiptirler.

2. Sınırlı sağlık okuryazarlığı, sağlığı önemli ölçüde etkiler. Sınırlı sağlık okuryazarlığı, sağlığın geliştirilmesi ve hastalık tanı faaliyetlerine daha az katılım, daha riskli sağlık tercihleri, daha fazla iş kazası, kronik hastalıkların yönetiminde azalma, ilaç tedavisine uyumsuzluk, artan hastaneye yatış ve yeniden hastaneye yatış, artan morbidite ve erken ölüm ile ilişkilidir.

3. Sınırlı sağlık okuryazarlığını sosyal statüdeki eşitsizlikler takip eder ve mevcut eşitsizlikleri güçlendirebilir.

Sınırlı sağlık okuryazarlığına sahip kişiler genellikle daha düşük eğitim düzeyine sahiptirler, yaşlı yetişkinlerdir, göçmendirler ve çeşitli halk transferi ödemelerine bağımlıdır.

4. Kişisel sağllk okuryazarlığı becerilerini ve yeteneklerini geliştirmek ömür boyu sürecek bir süreçtir.

Hiç kimse tam anlamıyla sağlık okuryazarı değildir herkesin bir noktada önemli sağlık bilgilerini anlama veya bunlara göre hareket etme konusunda yardıma ihtiyacı vardır.

5. Sağlık okuryazarlığı ile ilgili kapasite ve yeterlilik şartlara, kültüre ve ortama göre değişir. 
Bunlar, iletişim becerileri, sağlık konuları hakkında bilgi, kültür ve sağlık hizmetlerinin belirli özellikleri, halk sağlığı ve insanların sağlık bilgilerini edindikleri ve kullandıkları diğer ilgili sistemler ve ortamlar içeren bireysel ve sistem faktörlere bağlıdır.

6. Sağlık sistemlerinin duyarlılığı, olumlu sağlık sonuçlarına ulaşmayı kolaylaştırır.

Bir bireyin sağlık okuryazarlığı düzeyinin yeterliliği, sağlık ve diğer sektörlerdeki kuruluşların yanıt verme yeteneklerine ve hizmet almaları gereken sistemlerin karmaşıklığının bir sonucu olarak bireye yüklenen taleplere bağlıdır (2).

\section{DİABETES MELLİTUS}

Diabetes Mellitus, pankreasın yeterince insülin üretmediğinde veya vücut ürettiği insülini etkili bir şekilde kullanamadığında ortaya çıkan kronik bir hastalıktır. Hiperglisemi veya yüksek kan şekeri, kontrolsüz diyabetin yaygın bir etkisidir ve zamanla vücudun birçok sisteminde, özellikle sinirlerde ve kan damarlarında ciddi hasara yol açar. Diyabet, körlük, böbrek yetmezliği, kalp krizi, felç ve alt ekstremite ampütasyonunun başlıca nedenidir. Dünya çapında, 2014 yllında, 18 yaş ve üstü yetişkinlerin $\% 8,5$ 'i diyabet hastası olup, 2016 yllında tahminen 1,6 milyon ölüm doğrudan diyabetten kaynaklanmıştır (6). Türkiye'de diyabet prevalansı 2016 yllında \%13,2 olup, toplam ölümlerin ise \%2'si doğrudan diyabet nedeniyle gerçekleşmiştir (7). Son yayımlanan Uluslararası Diyabet Federasyonu Diyabet Atlası'na göre ülkemiz Avrupa ülkeleri arasında diyabet prevalansının en yüksek olduğu ülkedir. Benzer şekilde Avrupa'da 20-79 yaş arası en fazla diyabetli hastanın bulunduğu ülkeler sıralamasında ülkemiz 7 milyonu aşkın kişiyle Rusya ve Almanya'dan sonra 3. sırada yer almaktadır. Diyabetin en önemli risk faktörleri arasında sayılan obezitenin ülkemizde özellikle son yıllarda artış göstermesi bu sonucun ortaya çıkmasında önemli bir rol oynamaktadır (8).

\section{Diyabetin Sağlık Üzerine Etkisi}

- Zamanla diyabet kalbe, kan damarlarına, gözlere, böbreklere ve sinirlere zarar verebilir.

- Diyabetli yetişkinlerde kalp krizi ve felç riski iki ila üç kat artmaktadir.

- Ayaklarda kan akımının azalması, nöropati (sinir hasarı) ile birleştiğinde ayak ülseri, enfeksiyon ve nihayetinde uzuv ampütasyonuna duyulan ihtiyacı artırır.

- Diyabetik retinopati önemli bir körlük nedenidir ve retinadaki küçük kan damarlarında uzun süreli biriken hasarın bir sonucu olarak ortaya çıkar. Diyabet, küresel körlügün \%2,6’sının nedenidir.
- Diyabet, böbrek yetmezliğinin önde gelen nedenleri arasindadir (6).

Sağlık Okuryazarlığının Diyabet Üzerine Etkisine İlişkin Araştırmaların Sonuçları

Aşağıda, sağlık okuryazarlığı ve diyabet üzerine yapılan araştırmalardan elde edilen sonuçlardan bazıları sunulmaktadir.

- Chen ve ark.nın 2018 yılında yaptıkları bir meta-analiz çalışmasında, yetersiz sağlık okuryazarlığı olan kişilerde diyabetik ayak hastalığına yakalanma olasılığı, yeterli sağlık okuryazarlığına sahip kişilere göre yaklaşık iki kat daha fazla bulunmuştur (9).

- Hadden ve ark.nın 2019 yılında geriye dönük kohort analizi kullanarak yaptıkları çalışmada, diyabetik ayak amputasyonları grubundaki hastaların yetersiz sağlık okuryazarlığına sahip olma olasılı̆̆ı, genel ortopedik hasta grubundaki hastalara göre 8 kat daha yüksek olarak saptanmıştır (10).

- Kim ve Lee'nin 2016 yılında yaptıkları on üç çalışmayı içeren bir meta-analiz çalışmasında, genel olarak sağlık okuryazarlığına ilişkin duyarlı diyabet yönetimi müdahalelerinin Hemoglobin A1c düzeyini düşürmede etkili olduğu görülmüştür (11).

- Tseng ve ark.nın 2017 yilında Kuzey Tayvan'da tip 2 diyabet hastalarında yaptıkları çalışmada, yetersiz sağlık okuryazarlığının daha kötü glisemik kontrol ile önemli ölçüde ilişkili olduğu belirlenmiştir (12).

- Saeed ve ark. 2018 yılında Pakistan'da yaptıkları bir çalışmada, glisemik kontrolü kötü diyabetli hastaların çoğunluğunun yetersiz sağlık okuryazarlık düzeyine sahip olduğu ve bu hastaların retinopatiye sahip olma olasılığının da yüksek olduğu tespit edilmiştir (13).

- Wang ve ark.nın 2019 yılında Çin'de diyabet hastaları üzerinde yaptıkları randomize kontrollü bir çalışmada sağlık okuryazarlık ile ilgili müdahale uygulanan grupta kontrol grubuna göre Hemoglobin Alc düzeyi düşük bulunmuş olup, kan basıncı ve lipid kontrolünde önemli bir fayda gözlenmemiştir (14).

- Tefera ve ark.nın 2020 yılında Doğu Afrika'da tip 2 diabetes mellituslu yetişkin hastalarda yaptıkları bir çalışmada, diyabet okuryazarlığı yüksek olan hastaların, hedef glisemik kontrole ulaşma olasılı̆̆ yetersiz diyabetik okuryazarlığa sahip hastalara göre 1,85 kat daha fazla tespit edilmiştir (15).

- Finbråten ve ark.nın 2020 yılında tip 2 diyabet hastaları üzerinde yaptıkları bir çalışmada, yüksek sağlık okuryazarlığı seviyeleri, daha yüksek eğitim seviyeleri, daha iyi 
genel sağlık koşulları ve daha yüksek hasta tarafından algılanan güçlendirme ile ilişkilendirilmiştir. Ayrıca, bu çalışmada sağlık okuryazarlığı ile glisemik kontrol arasındaki bağlantıyı veya sağlık okuryazarlığı ile sağ lık davranışları arasındaki bağlantıyı güçlendiren hiçbir ampirik kanıt bulunamamıștır (16).

- Shin ve Lee'nin 2018 yllında Güney Kore'de 60 yaş ve üstü diyabet hastaları üzerinde yaptıkları bir çalışmada, yüksek sağllk okuryazarlığa sahip kişilerin daha güçlü olduğu ve daha yüksek güçlendirmeye sahip olanların sağlıklı yiyecekler yeme ve egzersiz yapma olasılıklarının daha yüksek olduğu gösterilmiştir (17).

- RobatSarpooshi ve ark.nın 2020 yılında İran'da diyabetli hastalar üzerinde yaptıkları bir çalışmada, sağlık okuryazarlığı yüksek olan kişilerin öz bakım davranışlarının daha iyi olduğu bulunmuştur (18).

- Kim ve Utz’un 2019 yilında Güney Kore'de diyabet hastaları üzerinde yaptıkları kontrollü bir çalışmada, sosyal medya temelli, sağlık okuryazarlığına duyarlı diyabet yönetimi müdahalesi, öz bakım uygulamalarını iyileştirmeye çalışırken yetersiz sağlık okuryazarlığına sahip kişilerin karşılaştığı dezavantajları azaltmada etkili olduğu gösterilmiştir (19).

- Kim ve ark.nın 2020 yllında tip 2 diyabetli Koreli Amerikalılar üzerinde yaptıkları randomize kontrollü bir çalışmada, sağlık okuryazarlığının öz bakım becerileri ve öz-yeterlik gibi aracılarla dolaylı olarak glikoz kontrolü ve yaşam kalitesini olumlu yönde etkilediği belirlenmiş$\operatorname{tir}(20)$.

- Akyol Güner ve ark.nın 2020 yılında Zonguldak'ta diyabetli bireyler üzerinde yaptıkları kesitsel bir çalışmada, diyabetli bireylerin sağlık okuryazarlık düzeyinin ve akılcı ilaç kullanımın yetersiz düzeyde olduğu ve diyabetli bireylerde sağlık okuryazarlığı ile akılcı ilaç kullanı$\mathrm{m}$ düzeyleri arasında ise pozitif yönlü ve yüksek düzeyde anlamlı bir ilişki olduğu belirlenmiştir (21).

\section{SONUÇ}

Sağlık okuryazarlığı düzeyinin yetersiz olması bireylerin ve toplumun sağllğ̆ını olumsuz yönde etkileyebilmektedir. Diyabetli hastalarda sağlık okuryazarlık düzeyi genelde yetersiz olup, diyabet ile ilgili bilgi eksikliğin öz yeterlilik ve öz bakım davranışlarıyla ilişkili olduğu görülmektedir. Yetersiz sağlık okuryazarlı̆̆ı ve yetersiz sayısal beceriler kötü glisemik kontrol ile ilişkili olup, multidisipliner diyabet eğitim ve yönetim programlarında okuryazarlığı ele almak önemli sağlık sonuçlarını iyileştirebilir. Savunmasız hastalar ve sağlık sistemleri arasındaki etkileşimi iyileştirmek için artan uluslararası destek göz önüne alındığında, sağlık okurya- zarlığ diyabet tedavisinin sunumunun optimize edilmesine muhtemelen önemli bir katkı sağlayacaktır. Sağlık okuryazarlığının artırılması, kişisel ve kolektif bilgi ve becerilerin geliştirilmesi ve duyarlı ortamların, sağlıklı politikalarının ve elverişli ortamların oluşturulması yoluyla vatandaşlar bu konuda güçlendirilebilir. Sağlık hizmeti sağlayıcıları, yetersiz sağlık okuryazarlığı olan kişileri diyabetin öz yönetim müdahalelerine dahil etmeye yönelik stratejilerin aktif uygulamasını düşünmelidir. Doktor, hemşire, diş hekimi, eczacı veya halk sağlığı çalıșanı gibi başkalarına sağlık bilgileri ve hizmetleri sağlayan herkesin sağlık okuryazarlığ becerilerine sahip olması gerekir.

Yazarların Makaleye Katkı Beyanı

Yazının fikir, kaynak, eleştirel yaklaşım ve yazımı yazarlar tarafından gerçekleştirilmiştir.

\section{Çıkar Çatışması}

Bu yazı için herhangi bir çıkar çatışması yoktur.

Finansal Destek

Herhangi bir finansal destek alınmamıştır.

\section{Etik Kurul Onayı}

Deneysel olmadığından veya insan materyali kullanılmadığından Etik Kurul oluru bulunmamaktadır.

\section{Hakem Değerlendirmesi}

Hakemlerin Değerlendirmeleri sonrası yayınlanmaya uygun bulunmuş ve kabul edilmiştir.

\section{KAYNAKLAR}

1. World Health Organization. (2020a). Health Literacy. https:// www.who.int/healthpromotion/health-literacy/en/. Erişim Tarihi: 02.09.2020

2. World Health Organization. (2020b). Why health literacy is important. https://www.euro.who.int/en/health-topics/ disease-prevention/health-literacy/why-health-literacyis-important\#: : text=Strong\%20health\%20literacy\%20 enables $\% 20$ people,political $\% 20$ leaders $\% 20$ and $\% 20$ policy\%2Dmakers. Erişim Tarihi: 02.09.2020

3. T.C. Sağlık Bakanlığı. Ankara İli Sincan İlçesi Birinci Basamak Sağlık Personelinde Sağlık Okuryazarlığı İle İlgili Eğitim Programı Geliştirilmesi. T.C. Sağlık Bakanlığı, Sağlığın Geliştirilmesi Genel Müdürlüğü, Yayın No:1085, Ankara, 2018.

4. Kickbusch I, Pelikan J, Apfel F, Tsouros A. Health literacy: the solid facts. Copenhagen: WHO Regional Office for Europe; 2013. https://www.euro.who.int/_data/assets/pdf_ file/0008/190655/e96854.pdf?ua=1. Erişim Tarihi: 02.09.2020.

5. Network of the National Library of Medicine (NNLM). (2020). Health Literacy. https://nnlm.gov/initiatives/topics/healthliteracy. Erişim Tarihi: 02.09.2020. 
6. World Health Organization. (2020c). Diabetes. https://www. who.int/health-topics/diabetes\#tab=tab_1. Erişim Tarihi: 02.09.2020.

7. World Health Organization. (2016). Diabetes country profiles (Turkey) 2016. https://www.who.int/diabetes/countryprofiles/tur_en.pdf?ua=1. Erişim Tarihi: 02.09.2020.

8. T.C. Sağlık Bakanlığı. (2020). Türkiye Diyabet Programı (2015-2020). https://extranet.who.int/ncdccs/Data/TUR_D1_ Türkiye\%20Diyabet\%20Programı\%202015-2020.pdf. Erişim Tarihi: 02.09.2020.

9. Chen PY, Elmer S, Callisaya M, Wills K, Greenaway TM, Winzenberg TM. Associations of health literacy with diabetic foot outcomes: A systematic review and meta-analysis. Diabet Med. 2018;35(11):1470-1479.

10. Hadden K, Martin R, Prince L, Barnes CL. Patient health literacy and diabetic foot amputations. J Foot Ankle Surg. 2019;58(5):877-879.

11. Kim SH, Lee A. Health-literacy-sensitive diabetes selfmanagement interventions: A systematic review and metaanalysis. Worldviews Evid Based Nurs. 2016;13(4):324-333.

12. Tseng HM, Liao SF, Wen YP, Chuang YJ. Stages of change concept of the transtheoretical model for healthy eating links health literacy and diabetes knowledge to glycemic control in people with type 2 diabetes. Prim Care Diabetes. 2017;11(1):2936.

13. Saeed H, Saleem Z, Naeem R, Shahzadi I, Islam M. Impact of health literacy on diabetes outcomes: A cross-sectional study from Lahore, Pakistan. Public Health. 2018;156:8-14.

14. Wang L, Fang H, Xia Q, Liu X, Chen Y, Zhou P, Yan Y, Yao B, Wei Y, Jiang Y, Rothman RL, Xu W. Health literacy and exercise-focused interventions on clinical measurements in Chinese diabetes patients: A cluster randomized controlled trial. E Clinical Medicine. 2019;17:100211.
15. Tefera YG, Gebresillassie BM, Emiru YK, et al. Diabetic health literacy and its association with glycemic control among adult patients with type 2 diabetes mellitus attending the outpatient clinic of a university hospital in Ethiopia. PLoS One. 2020;15(4):e0231291.

16. Finbråten HS, Guttersrud $\varnothing$, Nordström G, Pettersen KS, Trollvik A, Wilde-Larsson B. Explaining variance in health literacy among people with type 2 diabetes: The association between health literacy and health behaviour and empowerment. BMC Public Health. 2020;20(1):161.

17. Shin KS, Lee EH. Relationships of health literacy to selfcare behaviors in people with diabetes aged 60 and above: Empowerment as a mediator. J Adv Nurs. 2018;74(10):23632372.

18. RobatSarpooshi D, Mahdizadeh M, Alizadeh Siuki H, Haddadi M, Robatsarpooshi H, Peyman N. The relationship between health literacy level and self-care behaviors in patients with diabetes. Patient Relat Outcome Meas. 2020;11:129-135.

19. Kim SH, Utz S. Effectiveness of a social media-based, health literacy-sensitive diabetes self-management intervention: A randomized controlled Trial. J Nurs Scholarsh. 2019;51(6):661669.

20. Kim MT, Kim KB, Ko J, et al. Health literacy and outcomes of a community-based self-help intervention: A case of Korean Americans with type 2 diabetes. Nurs Res. 2020;69(3):210-218.

21. Akyol Güner T, Kuzu A, Bayraktaroğlu T. Diyabetli bireylerde sağlık okuryazarlığı ve akılcı ilaç kullanımı arasındaki ilişki. Türkiye Diyabet ve Obezite Dergisi. 2020;4(3):214-223. 